\title{
Mantra Sebagai Ide Penciptaan Musik Etnis Jampi
}

\section{Gigih Al Fajar ovra Wulanda ${ }^{1}$}

\begin{abstract}
Mantra is the title of a musical work with spells of West Kalimantan ethnic Malays as the main material for its work. The purpose of this composition is to express spell duality. The concept of duality here is a mantra that is useful as a medium of goodness and a second mantra as a medium for danger. The word mantra itself can be interpreted as words when spoken containing mystic or sacred.

Through the stages of exploration, improvisation, until finally the process of explicitly forming spells of musical composition can be seen as a form of music that has three parts. Covers the beginning, middle and end. This composition is played by two different idioms including ethnic musical instruments and ethnic Javanese musical instruments.
\end{abstract}

Keywords: dualism, spells, Malay, mystical

\begin{abstract}
Abstrak
Mantra adalah judul karya musik dengan mantra-mantra etnis Melayu Kalimantan Barat sebagai bahan utama penggarapannya. Tujuan dari komposisi ini adalah untuk mengekspresikan dualitas mantra. Konsep dualitas di sini adalah mantra yang berguna sebagai media kebaikan dan mantra kedua sebagai media untuk bahaya. Mantra kata itu sendiri dapat diartikan sebagai kata-kata ketika diucapkan mengandung mistik atau sakral.

Melalui tahapan eksplorasi, improvisasi, hingga akhirnya proses pembentukan secara eksplisit mantera komposisi musik dapat dilihat sebagai bentuk musik yang memiliki tiga bagian. Meliputi bagian awal, tengah, dan akhir. Komposisi ini dimainkan oleh dua idiom berbeda termasuk alat musik etnik dan alat music etnis Jawa Barat.
\end{abstract}

Kata kunci: dualisme, mantra, Melayu, mistik.

\section{Pendahuluan}

Musik merupakan cabang seni yang membahas dan menetapkan berbagai suara ke dalam pola-pola yang dapat dimengerti dan dipahami manusia (Eaton, 2010:20). Oleh karena itu pula musik dapat dimengerti sebagai hasil olah pikir maupun olah rasa dari manusia untuk manusia. Selain itu musik sendiri

\footnotetext{
${ }^{1}$ Mahasiswa Program Pascasarjana S-2 Penciptaan ISI Yogyakarta.
} 
merupakan bentuk seni yang melibatkan penggunaan bunyi secara terorganisir melalui kontinum waktu tertentu (Danesi, 2012:195). Hal tersebut berarti suatu musiktidak dapat dilepaskan dari aspek kompositoris yang dalam hal ini ialah durasi maupun aspek sejarah yang meliputi periodesasi waktu tertentu.Setiap musik memiliki karakteristiknya masing-masing, dimana kondisi sosio-kultural dari peradaban tertentu turut andil dalam diversitas musik yang ada selama ini.

Filsuf Yunani yang bernama Aristoteles, menyatakan bahwa musik adalah curahan kekuatan tenaga dan kekuatan tenaga penggambaran (visualisasi) yang berasal dari gerak rasa dalam suatu rentetan suara (melodi) yang berirama (Prier: 2009:123). Lewat berbagai definisi ontologis musik di atas semakin mengafirmasikan bahwa terjadinya sebuah musik merupakan suatu konsekuensi dari campur tangan manusia dalam mengolah impresi yang didapat lewat panca inderanya.

Penulis dalam kesempatan ini memilih Jampisebagai judul komposisi musik yang akan diangkat sebagai tugas akhir. Kata Jampi sendiri dapat diartikan sebagai kata-kata yang bilamana diucapkan mengandung mistis/bersifat sakral. Pemilihan Jampi sebagai judul komposisi yang akan diangkat disesuaikan dengan konsepsi serta tujuan utama dalam penggarapan komposisi ini yakni untuk mengekspresikan dualisme dari mantra-mantra. Selain itu, penulis berkeinginan untuk menyinergikan pengolahan konsep dengan menggunakan metode berfilsafat dari salah satu filsuf idealis Jerman yaitu Georg Wilhelm Friedrich Hegel. Metode Hegel yang dimaksud disini adalah tentang tritunggal dialektika yang berupa tesis, antitesis dan sintesis.

Terkait dengan mantra, penulis dalam hal ini merujuk pada mantra-mantra yang terdapat dalam budaya masyarakat Melayu Embau diKapuas HuluKalimantan Barat. Sebagai contoh diantaranya Ilmu Segarak Bumi yang mana mantra tersebut berfungsi sebagai pelindung diri dari kejahatan gaib pada saat berpergian.

Embau sendiri adalah nama suatu kecamatan di kawasan Kapuas Hulu, embau (baca: Mmaw) juga merupakan nama salah satu anak Sungai Kapuas Sungai yang terpanjang di Indonesia. Pada tahun 1800-1857 kawasan Embau, 
merupakan sebuah wilayah administrasi di bawah pusat administrasi kolonial Semitau dengan nama Embau.

\section{Rumusan Ide Penciptaan}

Penulis memperoleh sebuah deskripsi tentang proyeksi ataupun konsep bentuk garapan atau komposisi yang meliputi aspek musikal dalam hal ini instrumentasi maupun aspek pertunjukan. Komposisi ini dipentaskan dengan sebuah format kolaborasi antara beberapa instrumen Barat (orchestral instrument) yang meliputi instrumen tiup kayu (woodwind) dan beberapa instrumen gamelan yang berlaras pelog.

Aspek non-musikal (yang mendukung pementasan atau penyajian) dalam pertunjukan ini meliputi tempat atau ruang yang akan digunakan, tata cahaya serta tata suara. Penulis dalam hal ini memilih procenium(mini concert) sebagai jenis ruang yang akan di gunakan. Tata suara akustik menjadi pilihan penulis dalam penyajian komposisi dengan tidak menggunakansound system berupamic serta amplifier.Macam instrumen yang digunakan dalam pementasan yaitu klarinet, violin alto, kontra bass, bonang barung,bonang penerus, gender barung berlaras pelog bem, barung dan berlaras selendro, slenthem, vokal dan gong.

\section{Tujuan dan Manfaat Penciptaan}

Penciptaan karya musik ini bertujuan memberikan sebuah alternatif dalam menggarap sebuah karya musik yang relevan dengan situasi maupun kondisi kekinian, dimana hal ini berhubungan erat secara kontekstual dengan keadaan suatu masyarakat. Selain itu komposisi musik ini ditujukan sebagai sebuah referensi serta stimulus dalam hal pembaharuan khasanah musik pada umumnya.

Penulis sendiri sekaligus merujuk kepada hasil kreatifitas maupun lokal jenius hal praktik ilmu gaib dalam konteks "positif" yang sudah mulai ditinggalkan hari demi hari. Karya ini juga diharapkan dapat memberikan suatu kontribusi bagi masyarakat, karena kecenderungan masyarakat kita saat ini selalu menginginkan sesuatu yang baru sebagai akibat yang ditimbulkan oleh tingkat 
kejenuhan yang sangat tinggi. Selain itu manfaat bagi dunia akademik diantaranya ialah bertambahnya perbendaharaan repertoar musik.

Beberapa tinjauan sumber yang berupa referensi musikal (karya) pada karya musik Jampi adalah Komposisi berjudul "Mantra" karya komponis berkebangsaan Jerman bernama Karlheinz Stockhausen, Circles (1960) Karya seorang komponis bernama Luciano Berio merupakan salah satu orang terkenal dari Italia, Violin Phase dari Steve Reich pada tahun 1967 dan Glassworks karyaPhilip Morris Glass (Philip Glass).

\section{Metode (Proses) Penciptaan}

Permasalahan komposisi musik merupakan sesuatu yang sangat kompleks sekaligus menyenangkan, karena sebagai seorang komponis kita dapat bermainmain dengan imajinasi dan kerasionalan secara bersamaan. Kutipan dari pernyataan kedua komponis tersebut cukup menggambarkan suatu keadaan serta permasalahan komposisi dan proses penciptaan pada saat ini. Adapun dalam sebuah penggarapan karya seni, sebaiknya juga tidak mengesampinkan sisi-sisi estetis yang harus terkandung di dalam karya seni yang akan digarap. Maka dari itu teori-teori estetika menjadi penting, yang dalam hal ini berguna sebagai acuan dalam membuat sebuah karya seni.Beberapa poin di bawah ini merupakan sebuah metode atau proses penciptaan yang penulis lakukan demi mencapai sebuah hasil karya seni yang maksimal.

\section{Eksplorasi}

Alma M. Hawkins menuturkan bahwa tahapan ini termasuk berpikir, berimajinasi, merasakan, dan merespon objek yang dijadikan sumber penciptaan (Hawkins, 1990:27). Eksplorasi dalam hal ini berupa pengamatan secara langsung atau tidak langsung (Kajian pustaka) terhadap mantra dalam Melayu Embau yang sedemikian rupa menjadi alasan terbentuknya. 


\section{Improvisasi}

Improvisasi memberikan kesempatan yang lebih besar bagi imajinasi, seleksi dan mencipta dari pada eksplorasi(Hawkins, 1990:33). Penulis mencoba bereksperimen terhadap instrumen yang akan dipergunakan seperti mengolah nada, harmoni dan ritme. Selain itu juga penulis mulai mencoba menuangkan materi yang sebelumnya telah diamati menjadi sebuah komposisi musik. Aktivitas kompositoris sudah mulai dilakukan demi tersusunya sebuah komposisi yang estetis mulai dari melakukan proses imitasi kedalam sebuah instrument, pelebaran ritme, penyempitan interval nada sampai kemudian memainkannya dalam sebuah instrument agar penulis dapat memilah bunyi yang harmonis dan yang tidak harmonis.

\section{Komposisi}

Komposisi musik ini sangat sederhana dengan menggunakan idiom musik etnis atau tradisional Jawa (gamelan) yang memberikan keselarasan antar instrumen dimana hal tersebut merupakan esensi dari musik Jawa (karawitan).Instrument musik Barat juga digunakan dalam karya ini guna memberikan kesan yang baru saat berkolaborasi dengan instrument Timur. Penulis dalam komposisi musik ini menggunakan tangga nada kromatis, dan nada-nada disonan agar tidak menghilangkan karakter musik Barat dan sekaligus pengaplikasian teori-teori musik barat yang diharmonisasikan kepada instrument Timur agar menjadi satu kesatuan dalam sebuah komposisi musik.

\section{Ulasan Karya}

Langkah awal penulis untuk menciptakan sebuah komposisi musik adalah berusaha mendapatkan rangsangan awal yang mampu memberikan inspirasi dan menjadi pendorong atas terbentuknya ide-ide, dimana ide tersebut menjadi kerangka dasar konsep berkarya. Lewat ide yang diperoleh tersebut, penulis akhirnya mulai menentukan tema, judul, sampai bentuk maupun struktur komposisi yang akan dipergunakan. Selain itu berawal dari sebuah ide, merangsang penulis untuk menentukan elemen-elemen musikal seperti harmoni, 
dinamika, instrumen yang akan dipergunakan serta teknis-teknis dalam pembentukan karya

Melalui pengambilan tema, pada akhirnya penulis dapat menentukan batasan-batasan penggarapan komposisi musik yang nantinya dapat diterima oleh penonton tentang apa yang menjadi maksud dan tujuan komponis itu sendiri. Tema dalam komposisi musik ini adalah sisi dualism mantra suku Melayu Embau yang sekaligus juga menjadi awal mula terbentuknya ide-ide terkait aspek-aspek kompositoris seperti halnya bentuk maupun struktur.

Setelah menentukan tema yang akan diangkat, langkah penulis selanjutnya ialah menentukan judul komposisi musik. Pada kesempatan kali ini, Jampi dipilih sebagai judul karya. Kata Jampi sendiri dapat diartikan sebagai kata-kata yang bilamana diucapkan mengandung mistis/bersifat sakral. Pemilihan Jampi sebagai judul komposisi ini memiliki elemen penting yakni mantra, yang pada proses pengolahanya ditransformasikan kedalam sebuah komposisi musik.

\section{Bentuk (Form)}

Komposisi Jampi di bagi menjadi tiga bagian atau dengan kata lain merupakan komposisi yang mempunyai bentuk tiga bagian yakni bagian awal (A) bagian tengah (B) dan bagian akhir (C). Ulasan lebih lanjut dari masing-masing bagian akan di jabarkan sebagai berikut

1) Bagian $A$

Bagian pertama menggunakan tempo sedang (andante). Bagian ini mencoba menceritakan ataupun menggambarkan sifat mantra yang monoton dan sekaligus cenderung repetitif. Kesan nyaman pada musik bagian pertama ini juga diwujudkan untuk simbolisasi dari salah satu fungsi mantra yang berkhasiat sebagai media penyembuhan. Penulis juga berupaya merepresentasikan tiga hal dari mantra yang saling bertaut dan saling bergantung yakni mantra kepada manusia itu sendiri, mantra kepada alam jagad raya sampai mantra sebagai media penghantar kepada hal-hal yang bersifat kerohanian (transendental). 
Gong pada awal bagian yang berbunyi secara bersamaan dengan gender seperti gambar dibawah merupakan simbolisasi dari hal yang transenden bagaimana hal tersebut menjadi tingkatan tertinggi dalam kepercayaan lokal dan sekaligus yang menjadi salah satu unsur trilogi dari mantra suku melayu Embau.

2) Bagian (B)

JAMPI

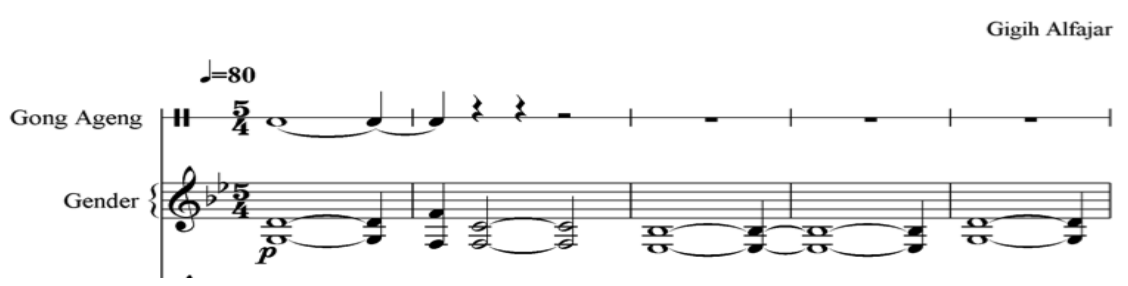

Bagian dua ini penulis berusaha menggambarkan tendensi serta elaborasi dari sisi eksternal mantra, khusunya mengaksentuasi sifat seram yang memberi impresi menakutkan. Fungsi mantra yang berguna memproteksi diri dari hal yang merugikan seperti yang ditimbulkan oleh mahluk gaib juga penulis representasikan pada bagian ini.

Secara keseluruhan bagian dua ini berdurasi sekitar sepuluh menit. Sukat 4/4 digunakan dalam bagian ini dan banyak menggunakan perubahan tempo, dinamika, teknik musik yang bersifat non konvensional yang bertujuan memerdekakan instrument serta gestur tubuh yang ikut andil dalam menyajikan sebuah ekpresi dalam struktur komposisi bunyi yang berjiwa estetis dalam bagian ini.

Fragmen utama bagian dua dengan tempo presto (kecepatan antara 170102 langkah permenit) ditambah dengan hentakan kaki untuk memberikan kesan gebrakan yang dimulai oleh instrument violin dan contrabass. Penggunaan nilai 1/16 juga mendominasi kedua instrument tersebut pada bagian ini, Untuk lebih jelasnya kita dapat mengamati secara langsung lewat potongan lagu dibawah ini. 
J A $\underset{\mathrm{M}}{\mathbf{M}} \mathbf{P} \mathbf{I}$
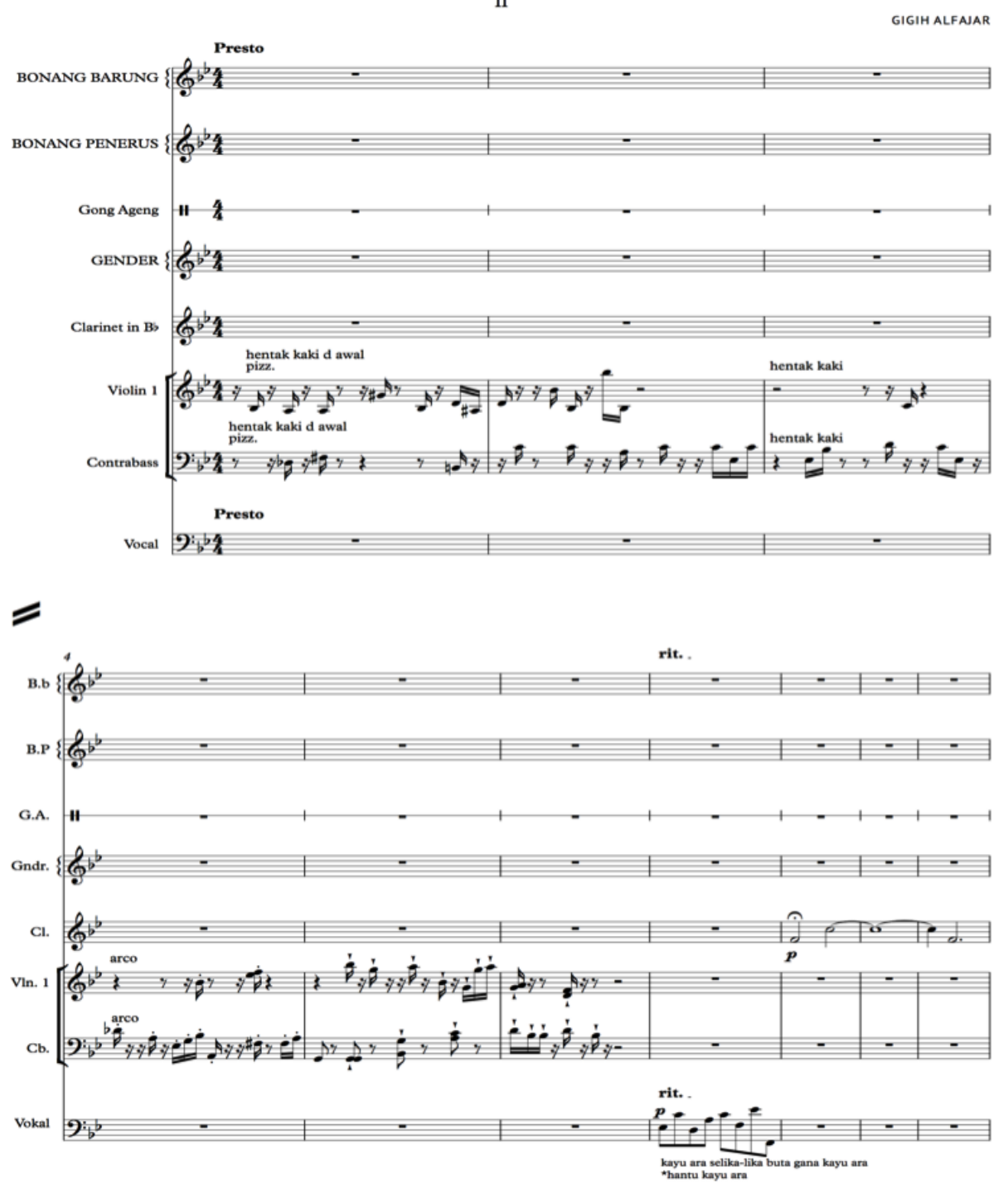

Bagian dua terdapat vokal yang sebelumnya memang secara sengaja tidak ditonjolkan. Khusus pada bagian dua ini unsur vokalitas sangat ditonjolkan guna memberikan bunyi yang ekspresif tapi tetap memberikan keselarasan satu kesatuan pada susunan komposisi dalam bagian ini. Terlihat jelas pada birama ketujuh fragmen awal bagian dua, permainan vokal yang terstrukutur masuk dengan dinamika piano sekaligus medapati perlambatan tempo/rit dengan 
rangkaian nada-nada yang berhimpitan atau yang biasa disebut dengan cluster. Dapat dilihat digambar dibawah ini.

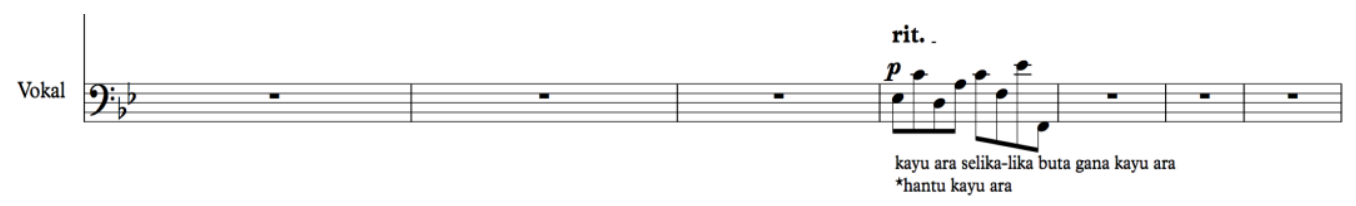

Permainan klarinet, khususnya pada birama enam puluh sembilan sangat ditonjolkan. Instrument klarinet disini menggunakan nada $D$ dan dengan pola yang terkesan monoton, diartikan sebagai efek samping dalam wujud sinyal batiniah yang tertangkap Pusoh (pengamal mantra) disaat sedang meminta ilmu hitam untuk kepentingan dirinya sendiri maupun untuk kepentingan orang yang meminta jasanya kepada kuasa gaib. Instrumen bonang penerus memainkan teknik kempyung Sedangkan instrument gender mendapatkan ruang untuk pengembangan nada dengan memainkan pola bebas dengan cengkok atau motif tabuhan nduduk, genduk kuning dan dua lolo Gambar potongan lagu fragmen lima dapat dilihat sebagai berikut :

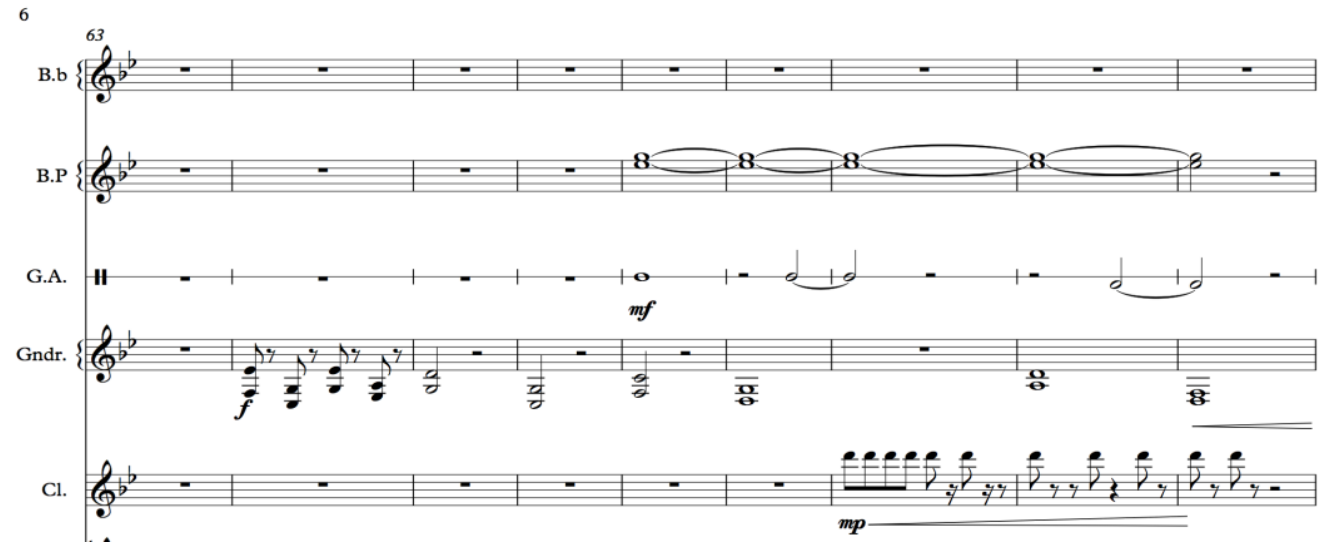

Instrument violin dan contrabass di fragmen keenam, menghadirkan kesan unison dalam segi ritme maupun interval. Kedua instrument tersebut menggunakan tonalitas yang berbeda seperti violin yang menggunakan tonalitas $E b M$, sedangkan contrabass dengan posisi tonalitas $B b M$. Permainan kedua instrument ini disatu sisi unisono akan tetapi mendapatkan dua tonalitas yang 
berbeda atau biasa juga disebut dengan (bitonality). Lihat potongan lagu dibawah ini:

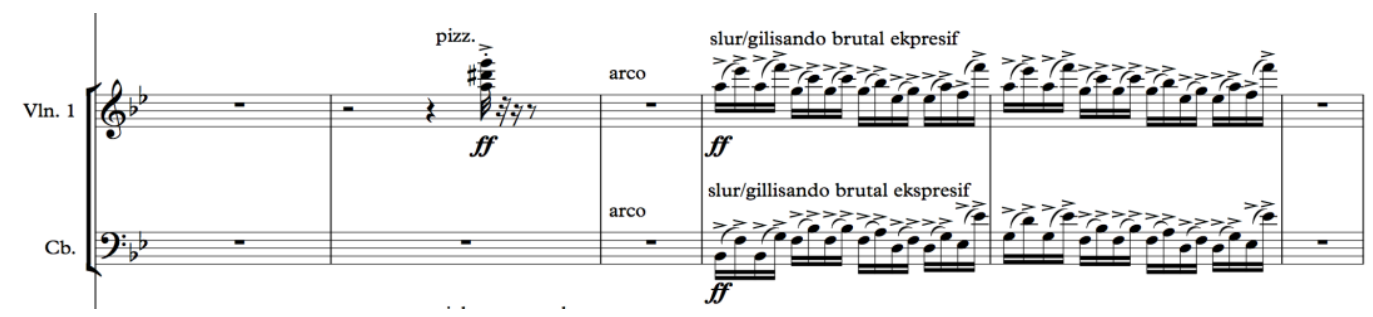

3) Bagian $\mathrm{C}$

Bagian tiga ini penulis menggambarkan perpaduan dari karakteristik dan khasiat mantra yang berkolerasi menjadi satu kesatuan. Hal tersebut menimbulkan kebahagian bagi orang yang berhasil memaknai mantra sebagai hal yang dapat mendekatkan diri kepada sang pencipta dan melindungi diri dari segala hal-hal yang dapat merugikan.

Bagian tiga secara keseluruhan menggunakan sukat $3 / 4$. Sukat $3 / 4$ disini berfungsi sebagai simbolisasi trilogy dari karakteristik mantra yakni Tuhan, alam dan manusia. Bagian ini juga kembali banyak menggunakan pengulangan atau repetisi guna memunculkan kembali gambaran karakter mantra yang monoton seperti pada bagian pertama. Setiap instrument disini bermain sebagai satu kesatuan harmoni dan ritme yang saling melengkapi satu sama lain seperti yang terjadi pada musik minimalis pada umunya.

Permainan instrument pada bagian ini diawali oleh bonang barung, gender barung, clarinet dan violin. Bonang barung barung mengawali bagian ini menggunakan teknik nyarug (seperti menyenggol bagian atas tabuhan) dan pekak (memperpendek perpanjangan suara) dengan tema melodi dilanjutkan dengan masuknya instrumen klarinet, klarinet serta violin yang secara keseluruhan menimbulkan kesan melodi $F m$ dan menggunakan dinamika mezzo-piano yang ditulis dengan simbol ( $m p)$. Gambar dibawah menjelaskan bagian awal pada bagian tiga ini. 


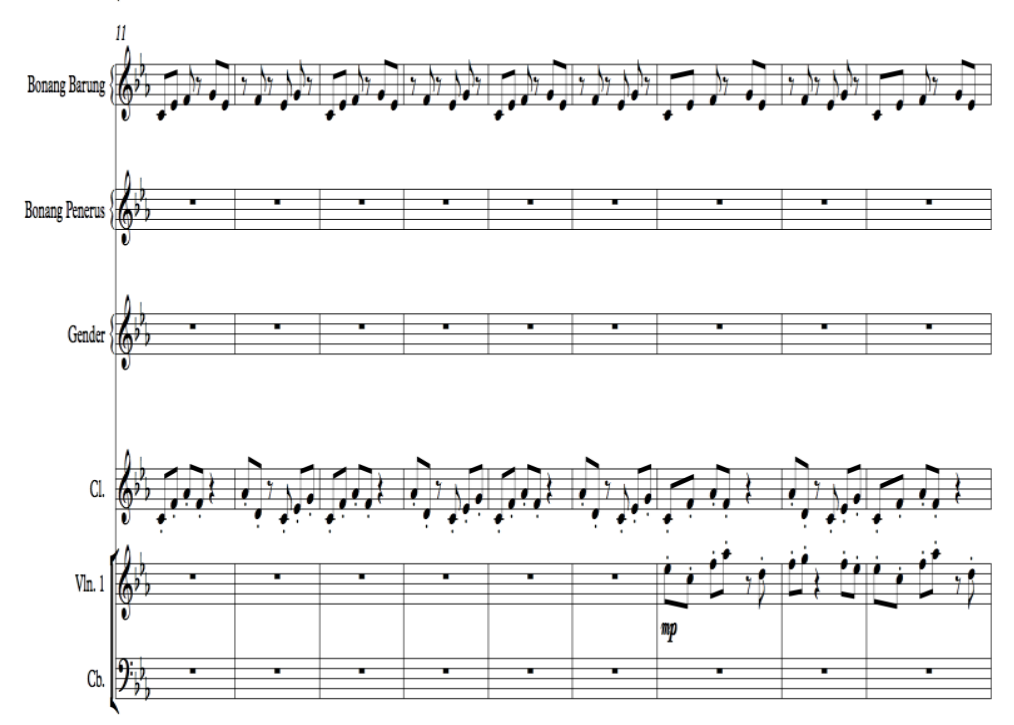

Kemudian pada garis birama ke 149 seiring hadirnya instrument string seperti violin dan contrabass dengan nada panjang berubah pula susunan progresi akordnya yang berubah menjadi $\mathrm{Cm}-\mathrm{Cm}_{4}^{6}-\mathrm{Cm}^{9}-\mathrm{Cm}_{4}^{6}$. Bagian ini juga mendapatkan penambahan seperti instrument bonang penerus yang masuk dan sekaligus memperbanyak pola ritme. Interaksi keharmonisan rasa suka dan duka pada masyarakat Embau dalam menggunakan mantra dimunculkan sebagai simbol yang dihadirkan instrument string dan instrumen-instrumen yang bersahutsahutan.
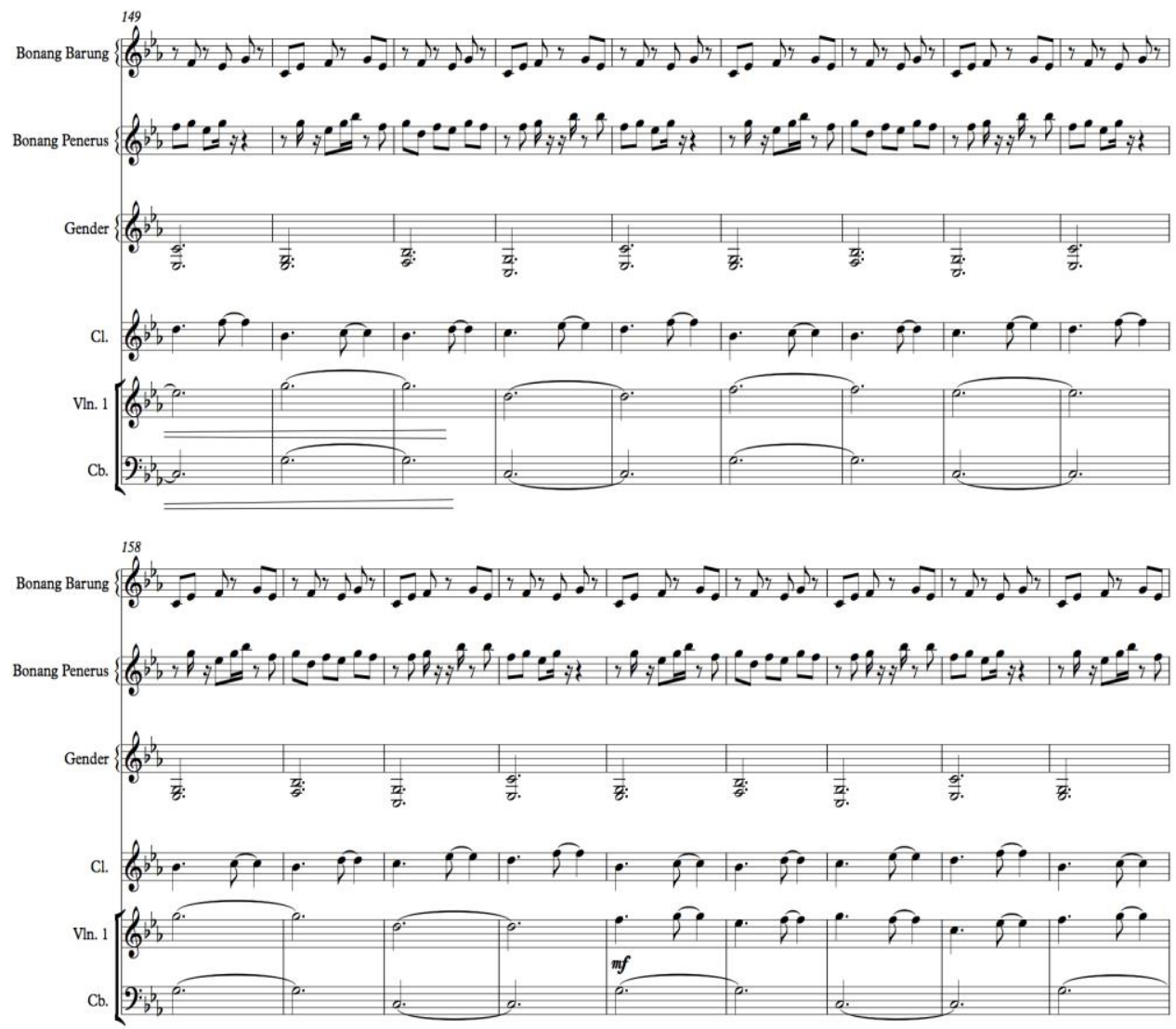
Bagian ini diakhiri dengan permainan seluruh instrumen dengan dinamika yang relatif kerass eperti bonang barung, clarinet dan violin dengan dinamika forte sedangkan bonang penerus bermain dengan dinamika fortesisimo menggambarkan korelasi dari karakteristik mantra yang semakin kuat memunculkan efek postif kebahagiaan dunia dan akhirat sesuai amalan yang baik pula dalam tatanan kehidupan masyarakat Embau. Setiap instrumen disini hadir membawakan pola melodi dan ritme yang telah dimainkan pada fragmen sebelumnya, terkecuali instrument bonang penerus yang bermain dengan ritme singkat dan oktaf yang tinggi sebagai media yang merepresentasikan alam semesta yang begitu luhur bagi peradaban manusia. Total rentang durasi secara keseluran berkisar tiga menit dan dimainkan dengan tempo allegro.

\section{Kesimpulan}

Penciptaan musik etnis ini secara garis besar berasaskan dari konsep dualisme mantra Melayu yang hidup di pedalaman Kalimantan Barat. Konsep dualisme tersebut disini antara lain adalah mantra yang berguna sebagai media untuk mendatangkan kebaikan dan yang kedua mantra sebagai media untuk menyakiti. Tertangkapnya konsep tersebut serta hasrat imaji yang mengikuti akhirnya mendorong penulis untuk langsung melakukan proses terciptanya peristiwa bunyi mulai dari eksplorasi, improvisasi sampai proses pembentukan untuk menjadi wujud yang termanifestasikan secara riil kepada khalayak apresiator.

Melewati proses mencipta serta analisa yang bertahap, secara eksplisit penulis akhirnya dapat merumuskan sebuah konstruksi yang konkret pada musik Jampi ini. Yakni musik yang dengan bentuk tiga bagian yang mengacu pada dialektika, metode berfilsfat dari Hegel. Ketiga bagian tersebut dibagian awal berupa tesis yang dalam konteks kekaryaan ini merupakan tipologi mantra mupun fungsi atau kegunaan mantra untuk hal-hal yang bersifat baik. Bagian tengah diikiuti dengan antitesisnya yang merupakan yang bertentangan dengan tesis. Sedangkan bagian akhir adalah sintesis, penggabungan dari kedua hal tersebut 
yang memiliki keberkaitan untuk saling bersinergi. Maka dari itu pula, penempatan bunyi harmonis dan disharmonis serta adanya pola permainan yang non konvensional diluar teknik komposisi pada umumnya menjadi harga mati bagi penulis dalam merepresentasikannya kedalam sebuah karya yang estetis.

Musik Jampi diperjalananya menemukan bagian yang dalam hal ini cukup membutuhkan kesabaran untuk melaluinya. Seperti penyampaian materi tentang teknis pola permainan komposisi yang dianggap para pemain sedikit merumitkan. Serta maksud dan tujuan musik dari konsepsi Jampi itu sendiri. Kesemuanya penulis tujukan agar dapat memberikan sajian yang akurat, sesuai dengan apa yang diinginkan penulis tanpa mengikat keleluasaan ekspresi dan persepsi para pemain, dalam menyajikan wujud manipulasi keindahan yang sedemikian mempesona kepada seluruh apresiator.

\section{Daftar Pustaka}

Banoe, Panoe. 2003. Kamus Musik. Yogyakarta: Kanisius.

Danesi, Marcel. 2012. Pesan Tanda dan Makna. Terjemahan Evi Setyarini dan Luci Lian Piantari. Yogyakarta: Jalasutra.

Hawkins, Alma M. 1990.Creating Through Dance.Terj. Y. Sumandiyo Hadi.Yogyakarta: Insitut Seni Indonesia Yogyakarta.

Hermansyah. Ilmu Gaib. 2010. Pontianak: Kepustakaan Populer Gramedia.

Lucy Wilkins,Margaret. 2006. Creative Music Composition. New York: Taylor \& Francis Group.

Khan, Hazrat Inayat. 2002. Dimensi Mistik dan Bunyi. Yogyakarta:Pustaka Sufi.

Kostka, Stefan. 2006. Materials and Techniques of Twentieth-Century Music. Third Edition. New jersey: Pearson Education

Mack, Dieter.1995. Ilmu Melodi. Yogyakarta: Pusat Musik Liturgi.

Mack, Dieter. 2009. Sejarah Musik Jilid 4. Yogyakarta: Pusat Musik Liturgi.

MacKinnon, Kathy. 2000. Ekologi Kalimantan. Jakarta: Prenhalindo. 
McDermott, Vincent.2013. Imagi-nation. Yogyakarta: Art Music Today.

Muelder, Eaton. 2010. Persoalan Dasar-Dasar Eestetika. Terjemahan Embun Kenyowati Ekosiwi. Jakarta: Salemba Humanika.

Prier, Karl-Edmund.2009. Kamus Musik. Yogyakarta : Pusat Musik Liturgi.

Bertrand, Russell. 2007. Sejarah Filsafat Barat. Yogyakarta: Pustaka Pelajar.

Titib, I Made. 2003. Teologi dan Simbol-Simbol Dalam Agama Hindu. Surabaya: Paramita.

Smith, Jacqueline.1985. Komposisi Tari, Terjemahan Ben Suharto. Yogyakarta: Ikalsti.

Sumandiyo Hadi, Y. 1990. Mencipta Lewat Tari. Yogyakarta: Institut Seni Indonesia Yogyakarta.

Sumardjo, Jakob.1999. Filsafat Seni. Bandung: ITB.

Sumarsam.2003. Gamelan: Interaksi Budaya dan Perkembangan Musikal di Jawa. Yogyakarta: Pustaka Pelajar.

Supanggah, Rahayu. 2007. Bothekan Karawitan II: Garap. Surakarta: Program Pascasarjana bekerja sama dengan ISI Press Surakarta. 